\title{
Television program avoidance and personality
}

Tabea Böcking and Andreas Fahr

E-mails: boecking@ifkw.Imu.de; fahr@ifkw.Imu.de

\begin{abstract}
Recent communication research indicates that approach and avoidance constitute two separate yet co-existing processes during media exposure. While many studies address TV approach behavior, little is known about TV avoidance behavior. Furthermore, personality has yet to be linked to avoidance behavior. This study analyzes the influence of personality on TV program avoidance. Data show that the "Big Five" personality characteristics (Neuroticism, Extraversion, Openness, Conscientiousness, Agreeableness) and Risk and Fight Willingness influence program avoidance, albeit to varying degrees. While the specific correlations are discussed in the paper, the results generally reveal that the combination of personality and avoidance has added value in terms of understanding of TV using behavior compared to the frequently analyzed link between personality and approach. For nearly all personality characteristics, data show that the avoidance perspective is more than the inversion of the approach perspective. The findings are discussed with reference to gratification and selectivity research.
\end{abstract}

Keywords: uses and gratifications, personality, selectivity, avoidance behavior, television

\section{Introduction}

In recent years, an increasing amount of research has been dedicated to the social and psychological origins of media use. The Uses-and-Gratifications Approach (UandG) is generally employed to describe and explain media use (for a summary, see Rubin, 2002). Some authors regard personality characteristics as a crucial factor in explaining approach behavior (e.g., Bommert et al., 2000). Although it remains questionable whether personality characteristics are predominant in this regard (Do- 
nohew et al., 1987; Kraaykamp, 2001), in some studies they explain media use to a greater degree than sociodemographic variables (Hall, 2005; Krcmar and Kean, 2005; Weaver, 2000). The commonly surveyed needs and motives can be considered as personality characteristics in a broader sense (Schmitt, 2004); however, they provide only a rough view on explaining media use.

In addition to considering sociological and psychological origins, UandG has recently been expanded in another direction: The literature typically uses the term "media use" regarding turning to media content; however, Fahr and Böcking (2009) and McLeod and Becker (1974) have shown that media response not only means turning to media content, but also turning away. Given that psychological characteristics are important for approach behavior, it is very likely that they are also important for avoidance behavior. The present study combines both perspectives and analyzes the influence of personality characteristics on the reasons for quitting a running TV program. More specifically, it focuses on the question of the extent to which personality dimensions explain TV program avoidance. This analysis is important in two ways: First, while considering the influence of users' personality, it clarifies the relation between exposure and avoidance, which are inevitably connected. Second, in doing so, it helps researchers as well as practitioners to further understand the process of TV use as a whole and to develop programs that are better suited to the audience's needs.

\section{Literature review}

\section{Avoidance behavior and personality}

Two problems exist that complicate research on the specific interrelation between TV program avoidance and personality characteristics: a lack of knowledge regarding the avoidance of TV programs and an almost unmanageable number of personality constructs that hypothetically could be used to explain avoidance behavior. Concerning the first problem, while motives of TV use have been empirically analyzed in numerous studies, few findings exist regarding avoidance behavior ${ }^{1}$. This small number of studies focus mainly on avoidance of media (TV) in general (Sicking, 2000) or some highly specific aspects of avoidance behavior (e. g., McLeod and Becker, 1974; van den Bulck, 2001; Walker and Bellamy, 1991). Situational TV-program avoidance in general was analyzed by Fahr and Böcking (2009), who mainly identified negative affects as a cause of changing channels (cf. Zillmann and Bryant, 1985; Perse, 1998). Their results also confirmed previous findings (McLeod and Becker, 1974) that avoidance motives are not only inverse gratifications, but also have their own meaning and underlying process. 
Psychological research supports this assumption that approach and avoidance are different processes. Carver et al. (2000) show that several sectors within psychology conceptualize approach and avoidance as the two core systems in the regulation of human behavior. One of the most popular theories stems from Gray (1990), who assumes a behavioral activation system (BAS) that moderates approach and a distinct behavioral inhibition system (BIS) that moderates avoidance behavior. These aspects support the importance of analyzing TV avoidance behavior separately from approach behavior. No previous study, however, has sought to attribute program avoidance to personality characteristics.

Concerning the second problem, psychological research offers a vast amount of personality constructs and items with which to measure the interrelation between TV program avoidance and personality characteristics. Due to the differing levels of abstraction and the mapping of different facets of personality, not all of these constructs are appropriate; moreover, it is generally not possible to directly compare them. Therefore, several authors (e.g., Weaver, 2003) have called for the use of broad, aligned inventories that embrace the basic dimensions of personality and that are validated with regard to content and measurement.

Several studies have analyzed TV use with respect to such basic personality inventories. However, even these studies have employed a variety of different inventories - mostly the "Big Five" (Costa and McCrae, 1992) or Eysenck's three-factor model (Eysenck and Eysenck, 1991) and commonly combine them with other single personality constructs. One popular single construct is sensation seeking, meaning "the seeking of varied, novel, complex, and intense sensations and experiences, and the willingness to take physical, social, legal, and financial risks for sake of such experiences" (Zuckerman, 1994: 27).

Not only have several studies proven that sensation seeking is an important predictor of TV viewing motives and behavior (e. g., Greene and Krcmar, 2005; Johnston, 1995; Krcmar and Greene, 1999; Perse, 1996; Slater, 2003), they have also demonstrated its close relation to the basic dimensions of personality (e. g., Aluja, García and García, 2003; Andresen, 2003; Zuckerman and Kuhlman, 2000). It thus seems necessary to include sensation seeking in any analysis of personality's influence on TV program avoidance. However, there is currently no coherent integration of this construct in TV use research.

The two problems outlined above influence the following, more detailed literature review. As there is no research that explicitly combines personality characteristics and TV avoidance behavior, from which we might derive specific hypotheses, we fall back on more general findings about TV use and link them with the existing findings of avoidance research. In the following, we provide a short summary of previous find- 
ings regarding the interaction of personality and viewing motives, as well as specific program preferences (cp. Krcmar and Greene, 1999). This summary is structured along the "Big Five" basic dimensions (Neuroticism, Extraversion, Openness, Conscientiousness, Agreeableness) and the closely related sensation-seeking construct. Based on this description, and linked with the theoretical implications of personality research itself, we derive the presumed influences of personality on avoidance behavior ${ }^{2}$.

\section{Personality, viewing motives and content preferences}

A great deal of research exists that employs a comprehensive personality inventory in analyzing the influence of personality on viewing motives and specific program preferences. The findings are largely consistent with research on neuroticism: Neurotic individuals dislike emotionally disturbing or distracting content (Burst, 1999; Conway and Rubin, 1991; Gunter, 1983; Kraaykamp and van Eijck, 2005; Weaver, 1991, 2000, 2003). However, some authors (e. g., Aluja-Fabregat and Torrubia-Beltri, 1998; Krcmar and Kean, 2005) come to the opposite conclusion.

Clearly, neurotic individuals generally experience stronger negative affects (Knobloch et al., 2000), although their specific handling of these affects can vary markedly. These findings can be explained by two contrary behavior patterns (Schmitt, 2004): While one part watches TV to distract and calm oneself, the other part looks for content congruent with one's disposition, thus also including disturbing content. A similar behavior is described by the sensitizer-represser concept (Vitouch, 1993), which can be assigned to Neuroticism in a broader sense. Sensitizers embark on an offensive fear-coping strategy and consciously expose themselves to fear-provoking content, while repressers pursue a defensive coping strategy and avoid such content. This presents the possibility that neurotic individuals will not turn off or switch a running program even if they evaluate it as being menacing or disgusting. However, this situation would be less likely if a neurotic individual was suddenly confronted with such negative affects. Consequently, it seems justified to assume that neurotic individuals will more frequently turn away from the running program if it provokes negative affects such as disgust, fear or dejection (Fahr and Böcking, 2009). This assumption is supported by personality psychology itself: The core of the Neuroticism dimension is represented by anxiousness, depression, low self-esteem and vulnerability (Eysenck, 1986; McCrae and John, 1992). It is likely that individuals with high scores on this dimension respond strongly to negative emotions and have a low threshold for negative information. Given that such 
individuals also prefer popular programs (Kraaykamp, 2001), they might be more tolerant of lowbrow programs.

Other findings also shed light on the influence of Extraversion on program choice and avoidance. Highly extraverted individuals prefer direct social contacts and therefore watch little TV (Finn, 1997; Krcmar and Kean, 2005; McIlwraith, 1998; Weaver, 2000, 2003). If they do watch TV, they prefer films dealing with human relationships (Burst, 1999) and (erotic) comedies and generally refuse adventure films (Weaver, 1991; Weaver et al., 1993). However, Krcmar and Kean (2005) identified a preference for various violent genres among extraverts. We can only assume the extent to which the avoidance of negative effects can explain these preferences, especially as the preferred violent films (and even films dealing with relationships) can provoke negative emotions.

Considering the relatively low TV use of extraverts and the minor influence of Extraversion on their using motives, this personality characteristic is likely to be only moderately connected to avoidance behavior. However, personality psychology itself suggests that extraverts should avoid media content that does not provide sufficient stimulation. For this reason, the Extraversion dimension is theoretically linked to activity, sociability, dominance and assertiveness (Eysenck, 1986; McCrae and John, 1992) - characteristics that mirror the need to achieve and maintain a hedonic arousal level. Taking these somewhat mixed aspects together, it is difficult to predict in greater detail the types of TV content likely to be avoided by extraverted people. However, because the relevant aspects of personality psychology are firmly rooted in theory and are accompanied by a great deal of empirical support, it is reasonable to assume that predictions with this basis would be accurate. We can therefore expect that individuals with high scores on Extraversion would avoid monotonous and non-social TV content.

For the Openness dimension of personality, communication research on TV exposure demonstrates few influences. Individuals with high Openness scores generally watch less TV (Finn, 1997) and prefer serious content (Kraaykamp, 2001; Kraaykamp and van Eijck, 2005) and information-based programs (Burst, 1999). These findings support the assumption that individuals with high Openness scores generally dislike inauthentic, monotonous or superficial programs. Personality psychology points in the same direction: Openness is connected to curiosity, activity and imagination (Eysenck, 1986; McCrae and John, 1992), meaning that people with high Openness scores respond positively to new information but are turned off by programs lacking in this regard.

There are even fewer findings regarding the Conscientiousness dimension of personality. Individuals with high scores on this dimension prefer popular content (Kraaykamp and van Eijck, 2005) and dislike thrilling 
and fictional programs. Burst (1999) attributes this behavior to the desire to avoid a loss of control. However, personality psychology indicates that compliance to social norms is the core element of Conscientiousness (Eysenck, 1986; McCrae and John, 1992). Consequently, individuals with high Conscientiousness scores are expected to avoid media content that portrays and approves norm-violating behavior.

The influence of Agreeableness on program preferences has been well documented. Individuals with high scores on this dimension prefer popular, non-disturbing content (Kraaykamp, 2001; Kraaykamp and van Eijck, 2005) and are thrill-sensitive (Knobloch et al., 2000); individuals with low scores watch more TV in general (Finn, 1997). The dimension also includes altruistic and friendly behavior, as well as their contradictions (see McCrae and John, 1992). Therefore, the findings regarding Eysenck's Psychoticism dimension can be subsumed under Agreeableness. High Psychoticism is expected to correlate with low Agreeableness to a certain extent. Overall, psychotics prefer violent content (Aluja-Fabregat and Torrubia-Beltri, 1998; Weaver, 1991), sex and horror (Weaver et al., 1993) and avoid romance and romantic comedies (Hall, 2005). Other studies have demonstrated a correlation between aggressiveness and a preference for violent content (e.g., Aluja-Fabregat and Torrubia-Beltri, 1998; Bushman, 1995; Slater, 2003). Moreover, Gunter (1983) reported that psychotic individuals are less sensible to media violence. With regard to program avoidance, highly agreeable individuals are generally expected to show a distinct tendency to discontinue watching running programs. It is likely that negative affects (e.g., disgust, fear and dejection) arising from disturbing or sensational content play an important role here (cp. Kraaykamp and van Eijck, 2005). However, personality psychology points in a somewhat different direction: The core of the Agreeableness dimension is a desire for social harmony, caring and pro-social behavior (Eysenck, 1986; McCrae and John, 1992). Against this background, people with high Agreeableness scores are expected to avoid media content that depicts and approves selfish antisocial behavior. A bridge to negative affects could be provided by the characteristic of tender-mindedness that is also part of the Agreeableness dimension (McCrae and John, 1992). It is likely that tender-minded individuals react strongly to content that evokes negative emotions. Consequently, high Agreeableness scores should be associated with the avoidance of anti-social and emotionally disturbing content.

In contrast to some of the "Big Five" discussed above, the influence of sensation-seeking on program preferences has been relatively well explored. Despite the use of highly differing and at times psychometrically insufficient operationalizations, research is largely unanimous in showing that sensation-seekers look for stimulation and thrilling entertain- 
ment and therefore prefer stimulating programs: They use TV in a relatively ritualistic manner (Burst, 1999; Conway and Rubin, 1991; Perse, 1996). They also favor high-arousal films (Banerjee et al., 2008), action and adventure programs (e.g., Burst, 1999; Krcmar and Greene, 1999; Perse, 1996), music programs (Perse, 1996; Potts et al., 1996), horror (Greene and Krcmar, 2005; Johnston, 1995; Zuckerman, 1996), erotic films (Bogaert, 2001; Burst, 1999; Zuckerman and Litle, 1986), violent films (Aluja-Fabregat, 2000; Slater, 2003) and daily talk shows and comedy (Potts et al., 1996). Moreover, sensation-seekers watch fewer information-based programs or shows, and change channels more often (Jandura and Schalm, 2001; Perse, 1996; Rowland et al., 1989). However, Jandura and Schalm (2001) found no relationship between sensation seeking and a preference for stimulating programs (cf. also Potts et al., 1996). Nevertheless, it is likely that sensation seekers are less sensitive to disgusting, thrilling or threatening program content, but more frequently discontinue watching monotonous programs and those that disparage risk-taking behavior. Conversely, it is likely that low-sensation seekers avoid such program content. The main facets of risk propensity and sensation seeking within personality psychology support these assumptions.

\section{Research questions and hypotheses}

The theoretical considerations discussed above lead to the following research question, with six specific hypotheses:

RQ: To what extent do personality dimensions explain program avoidance (in addition to sociodemography)?

$\mathrm{H}$ 1: The more neurotic an individual, the more he/she switches away from content that induces negative affects (disgust, fear, dejection) or prevents escapism. The less neurotic an individual, the less he/ she is expected to show any distinct avoidance behavior.

$\mathrm{H}$ 2: The more extraverted an individual, the more he/she avoids boring and unsociable TV programs. The less extraverted an individual, the less he/she is expected to show any distinct avoidance behavior.

$\mathrm{H}$ 3: The more open an individual to new experiences, the more often he/she turns away from non-authentic, boring, uninformative or superficial programs. The less open an individual, the less he/she is expected to show any distinct avoidance behavior.

$\mathrm{H}$ 4: The more conscientious an individual, the more he/she avoids content that depicts norm-violating behavior. The less conscientious an individual, the less he/she is expected to show any distinct avoidance behavior. 
H 5: The more agreeable an individual, the more he/she switches away upon feeling negative affects or being confronted with anti-social behavior. The less agreeable an individual, the less he/she is expected to show any distinct avoidance behavior.

$\mathrm{H}$ 6: The greater the degree to which an individual is a sensation seeker, the more he/she avoids boring, predictable or non-thrilling program content. The lesser the degree to which an individual is a sensation seeker, the less he/she is expected to avoid disgusting or frightening programs.

\section{Method}

\section{Participants}

To measure the influence of personality characteristics on the avoidance of TV program content, we conducted quantitative, self-administered paper-and-pencil interviews using a quota sample. The quota considered age, sex and education (encompassing three educational levels: (1) low, i. e., no school exam up to secondary general school, (2) middle, i.e., intermediate secondary school and (3) high, i.e., at least university of applied sciences entrance or general higher education) (cp. BMBF, 2004), and represented the German population 14 years of age and older. The interviews were conducted in 2004 by trained student interviewers who selected the interviewees according to the quotas, distributed the questionnaire and were present during completion of the questionnaire to answer any questions. As the interviewers recruited the participants from their hometowns during semester holidays, the interviews were conducted allover the country. A total of 264 participants took part in the study, $56.1 \%$ being female and $43.9 \%$ being male. Their ages ranged from 14 to 88 years ( $M=45.3$ years, $S D=17.4$ years), and educational levels were rather equally distributed with $34.1 \%$ having low, $37.8 \%$ having middle and $28.0 \%$ having higher education. Overall, the quota defaults were met; there were only marginal differences within the sample. In particular, women were slightly over-represented, while persons age 70 or older and those with a low level of education were slightly under-represented.

\section{Procedure}

Measures. The participants were asked to complete two questionnaires. The first asked for the reasons why, once decided upon, they chose to change a running program or switch off the TV completely (avoidance behavior; cp. van den Bulck's [2001, p. 176] "motivated avoidance”). The 
reasons consisted of 53 items identified in a theoretically and empirically guided qualitative preliminary study and were answered on a five-point Likert scale (see Appendix ${ }^{3}$ ). As the focus of the study is on TV program avoidance, the general characteristics represented by personality psychology were integrated into more specific, equivalent aspects of viewing behavior. Given that the presence of other persons influences program choice (Heeter and Greenberg, 1988), the avoiding motives were asked for in the context of solitary TV viewing. Moreover, the questionnaire asked for program preferences, the viewing frequency of several channels and the sociodemographical variables age, sex and education. The second questionnaire was the Hamburg Personality Inventory (HPI; Andresen, 2002), a personality inventory covering six basic dimensions. The HPI is similar to the NEO-FFI and is seen as a useful research instrument (Kieschke, 2003). Its first five dimensions are equivalent to the "Big Five." Moreover, the inventory includes a sixth dimension: Risk and Fight Willingness, congruent with Zuckerman's (1994) sensation-seeking factor, which has been proven to have a strong influence on TV viewing - it mainly represents the thrill and adventure-seeking subscale $(\mathrm{TAS})^{4}$.

Preliminary analyzes. Prior to analysis, we examined the distributions of the motive and personality variables. This led to the omission of three cases due to an excessive number of missing values. Given that the influence of personality on the avoidance motives was to be tested by hierarchical regression analysis, the variables were also analyzed for violation of regression assumptions, leading to the omission of another 15 cases. Based on a $p<.001$ criterion for Mahalanobis distance, these cases were identified as multivariate outliers. Ultimately, 246 cases remained for analysis, with all variables showing an approximately normal distribution and with only slight skewness. The sample population also met all assumptions of linearity, homoscedasticity of residuals and independence of errors and absence of multicollinearity.

A factor analysis ${ }^{5}$ was employed to reduce the item pool of the avoidance statements, resulting in six independent dimensions of avoidance: (a) authenticity, (b) disgust and repugnance, (c) dejection and loss of distance, (d) anger, dissonance and reactance, (e) sophistication and boredom and (f) anxiety and nervousness. Items loading less than .40 on a single factor were excluded. Although one of the items loaded on two factors simultaneously, it was included in the analysis because it represented both factors in an important way. (For the single items of each dimension, see the appendix; for more detailed information on the factor analysis, see Fahr and Böcking, 2009) 
In order to render our results more comprehendible, we provide a brief description of each avoidance dimension. While authenticity is mainly represented by trivial, superficial and, in a way, monotonous content, disgust and repugnance describes the avoidance of violent, vulgar, sexual and disrespectful - in short, disgusting - program content. The dejection and loss of distance dimension concentrates on excessive closeness to one's own life and undesired contemplation of about one's own surroundings and circumstances. Anger, dissonance and reactance encompasses the dislike of people and other opinions, as well as feeling defensive. Sophistication and boredom represents the avoidance of uninteresting or overly engrossing programs. Anxiety and nervousness is mainly represented by feelings of nervousness and fright.

\section{Results}

To identify the influence of personality on the avoidance motives, we employed hierarchical regressions, using the six avoidance dimensions as dependent variables. Our research question asked to what degree the variance of program avoidance can be explained by personality (in addition to sociodemography). To answer this question, sociodemographic variables (age, sex, education) ${ }^{6}$ were entered into the regression equation in the first step, followed by the six personality dimensions in the second step.

As shown in Tables 1 and 2, all avoidance dimensions except dimension four (anger, dissonance and reactance) can be significantly explained by sociodemography and/or personality. Moreover, the personality variables provide an additional explanation to the sociodemographic variables for almost all dimensions. Therefore, our data substantiates the proposal that personality is indeed an important and reliable predictor of TV exposure and avoidance behavior (cp. Hall, 2005; Krcmar and Kean, 2005; Weaver, 2000). Nonetheless, not all avoidance dimensions can be explained to the same extent by both sociodemography and personality.

The adjusted $R^{2}$ values indicate that the predictive value of the independent variables is by far the highest for program content that provokes disgust (e.g., depicting violence or sex). The avoidance dimensions authenticity and anxiety and nervousness also show a considerable influence by sociodemography and personality; the other dimensions can be explained only marginally by these factors. The increment in $R^{2}$ from step one to step two indicates that the additional predictive value of personality is highest for the avoidance of less authentic or lowbrow content, while the other dimensions generally do not significantly add to the additionally explained variance. In terms of ceasing to watch disgusting 


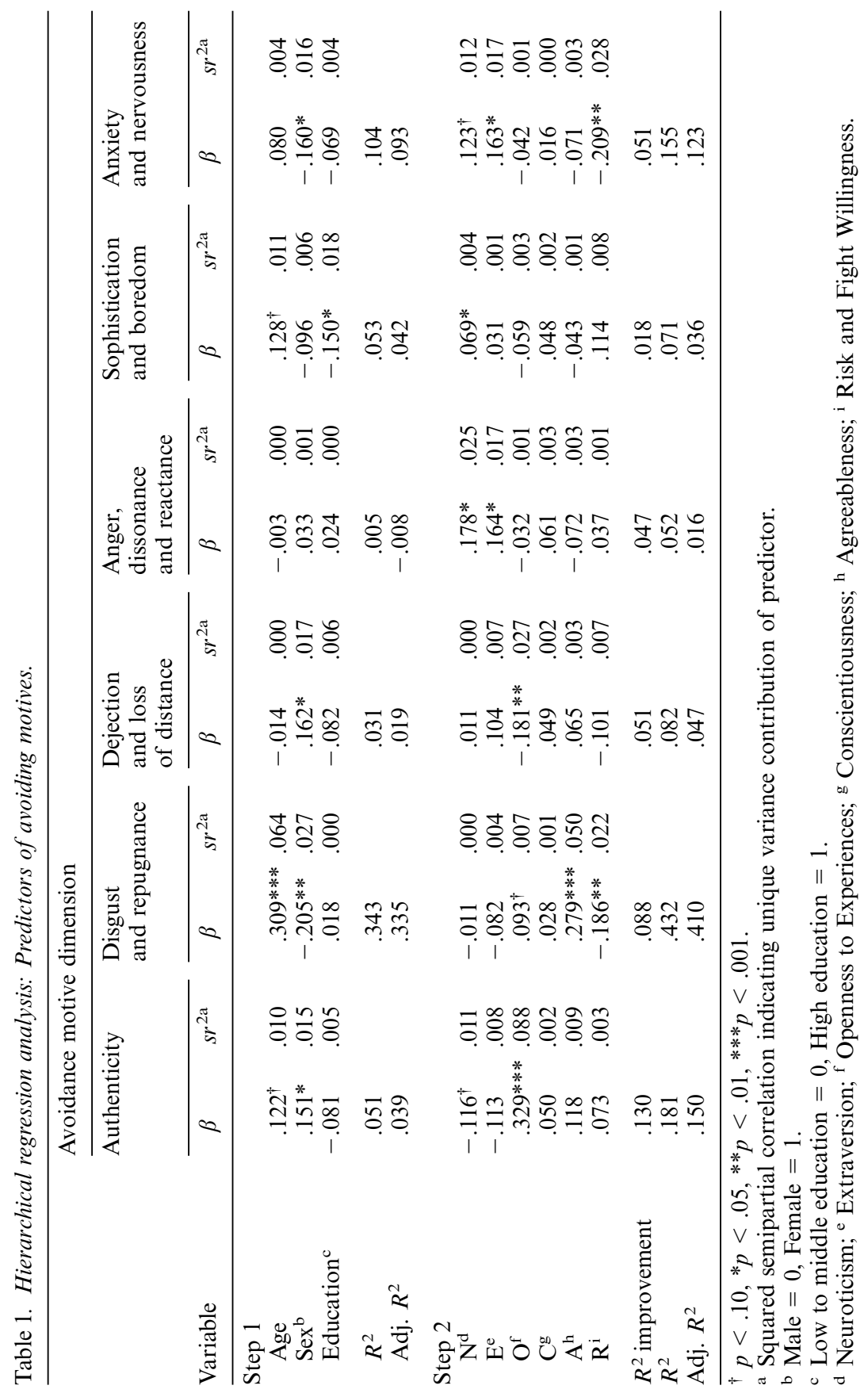


Table 2. Analysis of variance for the models of hierarchical regression analysis.

\begin{tabular}{|c|c|c|c|c|c|c|}
\hline \multirow[b]{3}{*}{ Avoidance motive dimension } & \multicolumn{6}{|c|}{ Step of hierarchical regression } \\
\hline & \multicolumn{3}{|c|}{ Step 1} & \multicolumn{3}{|c|}{ Step 2} \\
\hline & $d f$ & $F$ & $p$ & $d f$ & $F$ & $p$ \\
\hline Authenticity & 3,242 & 4.35 & .005 & 9,236 & 5.79 & .000 \\
\hline Disgust and repugnance & 3,242 & 42.15 & .000 & 9,236 & 19.92 & .000 \\
\hline Dejection and loss of distance & 3,242 & 2.58 & .054 & 9,236 & 2.35 & .015 \\
\hline Anger, dissonance and reactance & 3,242 & .38 & .770 & 9,236 & 1.43 & .175 \\
\hline Sophistication and boredom & 3,242 & 4.55 & .004 & 9,236 & 2.01 & .039 \\
\hline Anxiety and nervousness & 3,242 & 9.34 & .000 & 9,236 & 4.81 & .000 \\
\hline
\end{tabular}

content, age and sex show the highest predictive value. Sex is also an important predictor of avoiding fear-evoking content. This means that in both cases women change the channel when confronted with these types of content more frequently than men. Elderly people also avoid disgusting programs more often than younger people. Although several other slight influences of sex and education on program avoidance exist, we will not discuss these results in greater detail because our focus is on the additional influence of personality.

Before describing these results in greater detail, it must be noted that the avoidance dimensions and the personality characteristics presumably are confounded to some degree. The avoidance dimensions consist of some items that in a way also represent psychological characteristics. The HPI as a basic personality inventory covers a broad range of personality aspects and it is thus likely that there is some overlap. However, personality is a fundamental basis of human behavior in general and therefore such overlap could not to be avoided completely. Nevertheless, this problem must be kept in mind while interpreting the following results.

H 1 predicted that Neuroticism is positively related to avoidance of content that induces negative affects or prevents escapism. Indeed, highly neurotic individuals more frequently discontinue watching content that evokes their reactance; moreover, they avoid content for the reasons of sophistication or boredom. Congruent both with previous findings and our predictions, neurotic individuals tend to change the channel more frequently if they are scared. However, our expectations were not met regarding the avoidance behavior of less neurotic individuals: There is a slight tendency for those individuals to change the channel more often if the program lacks authenticity. In summary, our hypothesis concerning Neuroticism is only partially supported: In contrast to expectations, neurotic individuals do not seem to avoid negative af- 
fects in general, rather they try to avoid reactance and content with low escapist capability. Less neurotic individuals tend to however avoid superficial programs.

H 2 dealt with the influence of Extraversion on avoidance behavior. Theory suggested that strong Extraversion is positively correlated with the avoidance of monotonous and non-sociable TV programs. At first glance, however, the survey results are contrary to this assumption. Similar to neurotic individuals, strongly extraverted persons are especially likely to change the channel if they feel dissonance or reactance. They also avoid frightening programs more often than non-neurotics. However, a closer look at the single items within these dimensions provides some evidence in support of the hypothesis. The anxiety dimension also contains two items that can be interpreted as an expression of insufficient stimulation ("I cannot plunge into the story" and "I am not interested in the topics"), which was theoretically identified as avoidance motivation. However, it must be mentioned that some items of the other avoidance dimensions that do not show any correlation with Extraversion can also be interpreted as aspects of insufficient stimulation (e. g., "I can foresee what will happen"). Moreover, the items of the dissonance dimension are clearly unconnected to monotony or non-sociability.

On the one hand, these results show that at least the facet of nonsociability is relevant for the avoidance of TV in general, but is unimportant in terms of specific channel changing processes. On the other hand, the obtained data also indicate that the avoidance focus indeed broadens the using perspective. While the using perspective predominantly concentrates on the single motive of social companionship, the avoidance perspective includes a stronger emotional aspect. Although antipathy to specific people, which is included in this dimension, in a way also implies the social perspective, fear and insufficient involvement also addresses negative affects. In general, the impact of Extraversion is comparable to that of Neuroticism, being substantially greater than that of Conscientiousness.

$\mathrm{H} 3$ predicted that individuals who are open to new experiences avoid inauthentic, monotonous or superficial programs. Although Openness shows the highest single impact among the different avoidance dimensions, the results are only partially consistent with expectations: Individuals who are strongly open to new experiences do indeed change channels more often when a program is less authentic. However, boredom does not seem to be a reason for individuals with high Openness scores to change the channel; instead, there exists an unexpected influence of low Openness scores on avoidance behavior. Narrow-minded individuals more commonly avoid content that results in a loss of distance. Once 
again, the avoidance perspective broadens the traditional approach perspective.

H 4 utilized the personality dimension Conscientiousness to predict program avoidance. The results are only partially consistent with our expectations. Conscientiousness showed no impact on avoidance behavior, although the disgust and repugnance dimension in particular consists of items that, among others, represent norm-violating behavior. This means that avoiding norm-violating behavior is clearly not connected to avoiding specific TV content, as was predicted by personality psychology theory.

H 5 dealt with the influence of Agreeableness on avoidance behavior, predicting that highly agreeable individuals change the channel more frequently if they experience negative affects or are confronted with antisocial behavior. The results reveal a degree of support for both assumptions: The sole significant and rather high impact on the avoidance dimensions shows that very friendly individuals change the channel more frequently for reasons of disgust and repugnance. This avoidance dimension also consists of some items that mirror antisocial behavior (e.g., "people are mistreated" and "I think it is immoral"). However, contrary to our expectations, people with high Agreeableness scores show no stronger avoidance behavior in general when experiencing negative affects; they do not change the channel more frequently if they become depressed or frightened by the content. This result could be explained in part by previous findings that some people actively engage in sad emotions to sympathize with others, learn how to cope with their situation or enjoy the feeling of outdoing oneself (e. g., Oliver, 1993).

H 6 predicted that strongly risk-willing people (i.e., sensation seekers) avoid predictable and monotonous programs, while non-sensation seekers are expected to avoid disgusting or frightening programs. Again, the hypothesis is only partially supported by the data. In contrast to our expectations, risk-willing individuals do not change the program more often for reasons of sophistication or boredom. However, the results confirm the assumption that risk-adverse individuals change the channel more often if the program evokes disgust by presenting violence or sex, among other factors.

\section{Discussion}

This study was founded on the assumption that it is worthwhile to view media exposure not only from a sought and obtained gratifications point of view (i. e., approach behavior), but also to consider the role of avoidance processes in exposure to television content (cp. Fahr and Böcking, 2009). The obtained results are generally consistent with this assumption. 
As TV is increasingly becoming a background noise medium, avoidance processes might explain and predict program choice as well as approach processes do. The possible dimensions of these avoidance motives are thoroughly derived and discussed by Fahr and Böcking (2009), van den Bulck (2001), Perse (1998), Walker and Bellamy (1991), and McLeod and Becker (1974), among others. Studies in the tradition of the proactive uses and gratifications perspective have proven that personality is an important factor in explaining patterns of exposure to television from an approach perspective. Based on these two fundamentals, it seemed reasonable to analyze the role of personality in (program) avoidance behavior. The few studies that have focused on avoidance behavior in media use indicate that negative affects or emotions are important predictors in changing the channel. They also reveal that it is somewhat naïve to believe that negative affects evoked by media content always lead to avoidance behavior. We all know that we sometimes stick with displeasing content simply because it evokes "negative affects". The meta-effect is that the experience of enduring or overcoming one's immediate negative affects leads to the positive feeling of power, control and strength (Oliver, 1993). In addition, according to Gross (2001), one can differentiate between two basic types of strategies regarding emotion regulation that do not result in switching channels: reappraisal and suppression. The latter involves the suppression of negative feelings and therefore the tendency to initially continue media use, even when negative emotions are experienced. Reappraisal implies a cognitive change by re-interpreting the situation and therefore arriving at a different meaning (cp. also Vitouch, 1993). These examples show that there is no simple connection between specific personality characteristics and avoidance behavior.

Some people obviously act upon the aphorism "Do the thing you fear, and the death of fear is certain" Which people show this kind of viewing behavior? This question draws our attention to the relevance of personality factors in approach and avoidance behavior. Depending on the degree of individual distinctiveness of a personality dimension, different hypotheses regarding avoidance behavior have been drawn from the personality and media choice literature.

Taken together, the results reveal some important findings. Personality does help to explain program avoidance to a considerable extent, even when controlling for sociodemographic variables ${ }^{7}$. For almost all dimensions (except for Conscientiousness), one to three personality factors provide an additional explanation for program avoidance behavior. Some of the findings are consistent with prior research on program approach motives: Open-minded people avoid programs that lack authenticity and do not seek to avoid confrontations with themselves (dejection and loss 
of distance). Neurotic persons flee from negative feelings such as experienced anger, fear and dissonance. Agreeable people are particularly repulsed by disgusting content. These findings are consistent with common and sometimes naïve expectations that humans generally avoid negative experiences. Clearly, the impact of personality on avoidance behavior is strongly connected with unpleasant emotions. Moreover, avoidance behavior is primarily driven by loss minimization, thereby emphasizing the importance of including emotions in audience research.

The obtained data also reveal that we do not avoid negative emotions in general: Sensation seekers do not attempt to escape from several kinds of negative experiences (e. g., anxiety and disgust): rather they abide or even enjoy experiencing the emerging of negative emotions as well as the resulting feeling of pride about being able to cope with and overcome emotionally challenging situations. These findings help to explain in detail those factors responsible for special program choices (e.g., the penchant for horror, violence or modern phenomena such as trash TV), from a psychological viewpoint. The results also demonstrate the importance of working with a six-factor model of personality in media research - a model that includes sensation seeking as an additional dimension to the "Big Five" in an integrative personality inventory.

However, as already mentioned above, it should be kept in mind that personality characteristics and human behavior like program avoidance can represent two sides of the same coin. In extreme cases, this may lead to some kind of tautology in terms of "anxious people avoid scary programs". The aforementioned concept of meta-emotions, however, suggests that the correlations may be not that simple and also the results of this investigation support this assumption. Nonetheless, in some cases the existence of such confounded variables may make it difficult to interpret the results.

Regarding the low beta values of the personality characteristics' influence, it must also be noted that, according to the analysis method used here, only the explanation of variance exceeding the explanatory power of sociodemography is represented by these items. This means that the sociodemographic variables that were first entered in the regression probably explain some variance that could also have been explained by the personality characteristics alone. Therefore, it is rather likely that the betas of the personality characteristics would have been higher if the sociodemographic variables would have been omitted from the analysis. Moreover, studies in other fields of communication science, such as cultivation research or studies of the effects of media violence, also periodically arrive at similar low betas. It should furthermore be mentioned that the general personality characteristics used here on occasion show a rather trivial impact on the avoiding dimensions, as is consistent with 
previous studies that employed a comprehensive personality inventory (Knobloch et al., 2000). Depending on the research area, it could thus be useful to employ specific personality constructs if theoretical reasons can be given for their application. The present study, conducted with the aim of covering the entire scope of personality to gain an impression of its impact, employed a comprehensive personality inventory.

\section{Bionotes}

Tabea Böcking is Research Assistant at the Institute of Communication Research and Media Science, LMU Munich, Germany.

Andreas Fahr is Research Assistant at the Institute of Communication Research and Media Science, LMU Munich, Germany.

\section{Notes}

1. Within selectivity research, there exists a large amount of research that can be interpreted in terms of avoidance behavior. However, here we concentrate on research that explicitly focuses on avoidance behavior.

2. Considering that avoidance dimensions are not simply the mirror images of the corresponding gratifications, the influences of personality on ceasing to watch a TV program are expected to only partially correspond to the influences on turning to TV.

3. The appendix consists only of those 47 items that showed factor loadings $>.40$ in the preliminary factor analysis (cp. Fahr and Böcking, 2009).

4. The HPI thus contains only a part of the original sensation-seeking construct; nevertheless, development of the inventory reveals that the selectivity of the other sensation-seeking subscales is insufficient compared to the remaining five HPI dimensions (Andresen, 2002).

5. PCA; $K M O=.88$; extraction criteria: parallel analysis (Horn, 1965); varimax rotation.

6. To meet the requirements of regression analysis, the primarily three-staged education variable was dichotomized into (1) low to middle and (2) high education.

7. Considering that this study used hierarchical regression that involved entering the sociodemographic variables first, it seems plausible that the personality dimensions would explain a higher degree of variance if the sociodemographic variables were to be omitted.

\section{References}

Aluja, A., García, Ó., and García, L. F. (2003). Relationships among extraversion, openness to experience, and sensation seeking. Personality and Individual Differences, 35, 671-680.

Aluja-Fabregat, A. (2000). Personality and curiosity about TV and film violence in adolescents. Personality and Individual Differences, 29, 379-392.

Aluja-Fabregat, A., and Torrubia-Beltri, R. (1998). Viewing of mass media violence, perception of violence, personality and academic achievement. Personality and Individual Differences, 25, 973-989. 
Andresen, B. (2002). Hamburger Persönlichkeitsinventar: Manual [Hamburg personality inventory: Manual]. Göttingen, Germany: Hogrefe.

Andresen, B. (2003). Integration von Sensation Seeking in umfassende und geschlossene Modelle der Persönlichkeit [Integration of sensation seeking in comprehensive and complete models of personality]. In M. Roth and P. Hammelstein (Eds.), Sensation Seeking - Konzeption, Diagnostik und Anwendung (pp. 52-76) [Sensation seeking - conception, diagnostics and application]. Göttingen, Germany: Hogrefe.

Banerjee, S. C., Greene, K., Krcmar, M., Bagdasarov, Z., and Ruginyte, D. (2008). The role of gender and sensation seeking in film choice. Journal of Media Psychology, 20(3), 97-105.

Bogaert, A. F. (2001). Personality, individual differences, and preferences for the sexual media. Archives of Sexual Behavior, 30(1), 29-53.

BMBF. (2004). Bildung in Deutschland [Education in Germany]. Retrieved March 18th, 2009, from http://www.bmbf.de/pub/bildung_in_deutschland.pdf.

Bommert, H., Dirksmeier, C., and Kleyböcker, R. (2000). Differentielle Medienrezeption [Differential media use]. Münster, Germany: LIT.

Burst, M. (1999). Zuschauerpersönlichkeit als Voraussetzung für Fernsehmotive und Programmpräferenzen [Audience personality as requirement for viewing motives and program preferences]. Medienpsychologie, 11(3), 157-181.

Bushman, B. J. (1995). Moderating role of trait aggressiveness in the effects of violent media on aggression. Journal of Personality and Social Psychology, 69, 950-960.

Carver, C. S., Sutton, S. K., and Scheier, M. F. (2000). Action, emotion, and personality: Emerging conceptual integration. Personality and Social Psychology Bulletin, 26(6), $741-751$.

Conway, J. C., and Rubin, A. M. (1991). Psychological predictors of television viewing motivation. Communication Research, 18(4), 443-463.

Costa, P. T., and McCrae, R. R. (1992). Revised NEO Personality Inventory (NEO $P I-R)$ and NEO Five Factor Inventory. Professional manual. Odessa, FL: Psychological Assessment Resources.

Donohew, L., Palmgreen, P., and Rayburn II, J. D. (1987). Social and psychological origins of media use: A lifestyle analysis. Journal of Broadcasting and Electronic Media, 31(3), 255-278.

Eysenck, H. J. (1986). Models and paradigms in personality research. In A. Angleitner, A. Furnham and G. van Heck (Eds.), Personality psychology in Europe: Vol. 2. Current trends and controversies (pp. 213-223). Lisse, The Netherlands: Swets and Zeitlinger.

Eysenck, H. J., and Eysenck, S. B. G. (1991). Manual of the Eysenck personality scales (EPS adult). London: Hodder and Stoughton.

Fahr, A., and Böcking, T. (2009). Media choice as avoidance behavior: Avoidance motivations during television use. In T. Hartmann (Ed.), Media choice: A theoretical and empircial overview (pp. 185-202). New York: Routledge.

Finn, S. (1997). Origins of media exposure. Linking personality traits to TV, radio, print, and film use. Communication Research, 24(5), 507-529.

Gray, J. A. (1990). Brain systems that mediate both emotion and cognition. Cognition and Emotion, 4, 269-288.

Greene, K., and Krcmar, M. (2005). Predicting exposure to and liking of media violence: A uses and gratifications approach. Communication Studies, 56(1), 71-93.

Gross, J. J. (2001). Emotion regulation in adulthood: Timing is everything. Current Directions in Psychological Science, 10, 214-219.

Gunter, B. (1983). Personality and perceptions of harmful and harmless TV violence. Personality and Individual Differences, 4, 665-670. 
Hall, A. (2005). Audience personality and the selection of media and media genres. Media Psychology, 7(4), 377-398.

Heeter, C. and Greenberg, B. S. (1988). Cable and program choice. In D. Zillmann and J. Bryant (Eds.), Selective exposure to communication (pp. 203-224). Hillsdale, NJ: Erlbaum.

Horn, J. L. (1965). A rationale and test for the number of factors in factor analysis. Psychometrika, 30, 179-185.

Jandura, O., and Schalm, L. (2001). Sensation seeking on television. The relationship between sensation seeking and the use of television. Wissenschaftliche Zeitschrift der Technischen Universität Dresden, 50(1/2), 35-39.

Johnston, D. D. (1995). Adolescents' motivations for viewing graphic horror. Human Communication Research, 21(4), 522-552.

Kieschke, U. (2003). Hamburger Persönlichkeitsinventar (HPI) [Hamburg Personality Inventory]. In E. Fay (Ed.), Tests unter der Lupe 4. Aktuelle psychologische Testverfahren - kritisch betrachtet (pp. 36-48) [Tests checked out 4. Actual psychological test methods - critical reviewed ]. Göttingen, Germany: Vandenhoeck and Ruprecht.

Knobloch, S., Schramm, H., and Vorderer, P. (2000). "Big Five" und Rezeptionserleben. Einfluss der Zuschauerpersönlichkeit auf das Erleben von fiktionalen Filmen ["Big Five" and reception experience. Influence of user personality on the experience of fictional films]. Paper presented at the "Medienpsychologie" Division of the German Psychological Association (DGP) Conference, February $20^{\text {th }}$ $22^{\text {th }}, 2000$, in Köln, Germany.

Kraaykamp, G. (2001). Parents, personality and media preferences. Communications, 26(1), 15-38.

Kraaykamp, G., and van Eijck, K. (2005). Personality, media preferences, and cultural participation. Personality and Individual Differences, 38, 1675-1688.

Krcmar, M., and Greene, K. (1999). Predicting exposure to and uses of television violence. Journal of Communication, 49, 24-45.

Krcmar, M., and Kean, L. G. (2005). Uses and gratifications of media violence: Personality correlates of viewing and liking violent genres. Media Psychology, 7(4), 399-420.

McCrae, R. R. and John, O. P. (1992). An introduction to the five-factor model and its applications. Journal of Personality, 60, 175-215.

McIlwraith, R. D. (1998). 'I'm addicted to television': The personality, imagination, and TV watching patterns of self-identified TV addicts. Journal of Broadcasting and Electronic Media, 42, 371-386.

McLeod, J. M., and Becker, L. B. (1974). Testing the validity of gratification measures through political effects analysis. In J. G. Blumler and E. Katz (Eds.), The uses of mass communications. Current perspectives on gratification research (pp. 137164). Beverly Hills, CA: Sage.

Oliver, M. B. (1993). Exploring the paradox of the enjoyment of sad films. Human Communication Research, 19, 315-342.

Perse, E. M. (1996). Sensation seeking and the use of television for arousal. Communication Reports, 9(1), 37-48.

Perse, E. M. (1998). Implications of cognitive and affective involvement for channel changing. Journal of Communication, 48(3), 49-68.

Potts, R., Dedmon, A., and Halford, J. (1996). Sensation seeking, television viewing motives, and home television viewing patterns. Personality and Individual Differences, 21(6), 1081-1084.

Rowland, G., Fouts, G. T. and Heatherton, T. (1989). Television viewing and sensation seeking: uses, preferences and attitudes. Personality and Individual Differences, 10, 1003-1006. 
Rubin, A. M. (2002). The uses-and-gratifications perspective of media effects. In J. Bryant and D. Zillmann (Eds.), Media Effects. Advances in theory and research (pp. 525-548). Mahwah, NJ: Erlbaum.

Schmitt, M. (2004). Persönlichkeitspsychologische Grundlagen [Basic principles of personality psychology]. In R. Mangold, P. Vorderer and G. Bente (Eds.), Lehrbuch der Medienpsychologie (pp. 151-173) [Textbook of media psychology]. Göttingen, Germany: Hogrefe.

Sicking, P. (2000). Leben ohne Fernsehen. Eine qualitative Nichtfernseherstudie [Life without television. A qualitative examination of non-viewers]. Wiesbaden, Germany: DUV.

Slater, M. D. (2003). Alienation, aggression, and sensation seeking as predictors of adolescent use of violent film, computer, and website content. Journal of Communication, 53, 105-121.

Van den Bulck, J. (2001). News avoidance. The paradox of viewer selectivity. In K. Renckstorf, D. McQuail and N. Jankowski (Eds.), Television news research: Recent European approaches and findings (pp. 173-184). Berlin, Germany: Quintessenz.

Vitouch, P. (1993). Fernsehen und Angstbewältigung. Zur Typologie des Zuschauerverhaltens [Television and fear coping. Towards a typology of viewer behaviour]. Opladen, Germany: Westdeutscher Verlag.

Walker, J. R. and Bellamy, R. V. (1991). The gratifications of grazing: An exploratory study of remote control use. Journalism Quarterly, 68, 422-431.

Weaver, J. B. III. (1991). Exploring the links between personality and media preferences. Personality and Individual Differences, 12, 1293-1299.

Weaver, J. B. III. (2000). Personality and entertainment preferences. In D. Zillmann and P. Vorderer (Eds.), Media entertainment: The psychology of its appeal (pp. 235-248). Mahwah, NJ: Erlbaum.

Weaver, J. B. III. (2003). Individual differences in television viewing motives. Personality and Individual Differences, 35, 1427-1437.

Weaver, J. B. III, Brosius, H.-B., and Mundorf, N. (1993). Personality and movie preferences: A comparison of American and German audiences. Personality and Individual Differences, 14, 307-315.

Zillmann, D., and Bryant, J. (1985). Affect, mood, and emotion as determinants of selective exposure. In D. Zillmann and J. Bryant (Eds.), Selective exposure to communication (pp. 157-190). Hillsdale, NJ: Erlbaum.

Zuckerman, M. (1994). Behavioral expressions and biosocial bases of sensation seeking. New York: Cambridge University Press.

Zuckerman, M. (1996). Sensation seeking and the taste for vicarious horror. In J. B. Weaver and R. Tamborini (Eds.), Horror films: Current research on audience preferences and reactions (pp. 147-160). Mahwah, NJ: Erlbaum.

Zuckerman, M. and Kuhlman, D. M. (2000). Personality and risk-taking: Common biosocial factors. Journal of Personality, 68(6), 999-1029.

Zuckerman, M. and Litle, P. (1986). Personality and curiosity about morbid and sexual events. Personality and Individual Differences, 7(1), 49-56.

\section{Appendix: Dimensions of program avoidance}

1. Authenticity

I change the channel when ...

... it is trivial / undemanding.

$\ldots$ the people are superficial.

$\ldots$ it is not plausible. 
... it is stereotyped / full of clichés.

... it has nothing to do with real life.

... the description of men and women is biased.

$\ldots$ it is unprofessional / poor.

... the pictures seem too artificial.

... the program does not provide me with topics to discuss.

... the program is superficial.

... I can foresee what will happen.

... the people do not interest me.

... I feel treated like a child.

2. Disgust and repugnance

I change the channel when ...

... violence is shown.

$\ldots$ it is offensive and vulgar.

... it shocks me.

... sex is shown.

... I find it disgusting.

... people are mistreated.

... animals are mistreated.

... I think it is immoral.

$\ldots$ it is very loud and shrill.

... I am scared.

... minorities are portrayed negatively.

... I feel embarrassed.

3. Dejection and loss of distance

I change the channel when ...

... it reminds me of my own life.

... the program makes me brood about something.

... the people remind me of my peers.

... it concerns me personally.

$\ldots$ it gets too realistic / too genuine.

... it makes me feel sad.

... the program emotionally exhausts me.

... they show people suffering.

4. Anger, dissonance and reactance

I change the channel when ...

... I do not appreciate the expressed opinions.

... I do not like the people.

... I feel treated as an idiot.

... the people apparently do not have any idea.

... I think they try to give me feelings of guilt.

... the people talk in an unpleasant manner.

\section{Sophistication and boredom}

I change the channel when ...

... I cannot really forget my everyday life.

... I cannot unwind watching.

... I do not get to know anything new.

... I see pictures repeatedly.

$\ldots$ it is boring. 
6. Anxiety and nervousness

I change the channel when ...

... I cannot plunge into the story.

... it makes me nervous.

... I am scared.

... I am not interested in the topics. 